Research Article

\title{
Breaking Mechanism and Damage Evolution Rule of Ultra-High-Pressure Water Jet Impacting Steel Fiber Reinforced Concrete
}

\author{
Jialiang Liu $\mathbb{C D}^{1,2}$ Yuelong Chen ${ }^{10},{ }^{1,2}$ and Yujie Zhu $\mathbb{D}^{1,2}$ \\ ${ }^{1}$ State Key Laboratory of Mountain Bridge and Tunnel Engineering, Chongqing Jiaotong University, Chongqing 400074, China \\ ${ }^{2}$ Civil Engineering College, Chongqing Jiaotong University, Chongqing 400074, China \\ Correspondence should be addressed to Jialiang Liu; liujialiang@cqjtu.edu.cn
}

Received 17 December 2020; Revised 8 March 2021; Accepted 20 March 2021; Published 14 April 2021

Academic Editor: Jiang $\mathrm{Hu}$

Copyright (c) 2021 Jialiang Liu et al. This is an open access article distributed under the Creative Commons Attribution License, which permits unrestricted use, distribution, and reproduction in any medium, provided the original work is properly cited.

\begin{abstract}
Based on smooth particle hydrodynamics (SPH) method, this paper carried out the numerical simulation of ultra-high-pressure water jet (UHP-WJ) impacting steel fiber reinforced concrete (SFRC), verified the established numerical model by UHP-WJ impacting SFRC and computed tomography (CT) scanning experiments, and explored breaking mechanism and damage evolution rule of SFRC impacted by UHP-WJ. Results indicate that in the weak effect zone of steel fiber, the failure of concrete is generated and developed along the axial direction of UHP-WJ into a bowl-shaped crater with the combining action of compressive stress and shear stress. In the affected area of steel fiber, due to the inhomogeneity in the contact area of steel fiber and concrete, the stress concentration in the contact area is produced, causing the formation of propagated crack along the steel fiber. And the steel fiber has an obstruction effect on the development of broken bodies on the upper and lower sides of steel fiber. With the sustained action of UHP-WJ, the steel fiber in the intense radiation area of stress waves takes place fracture and finally the broken bodies on the upper and lower sides of steel fiber fuse. In addition, based on the CT scans and digital image processing technology, this paper also comparatively analyzed the internal fragmentations of SFRC and the ordinary concrete subjected to UHP-WJ impact, and it is found that compared with the ordinary concrete, there is smaller dimension of crater and it is difficult to engender macrocrack for SFRC, with lower damage and higher damage attenuation speed along the axial and radial directions.
\end{abstract}

\section{Introduction}

Concrete is one of the most widely used construction materials in the world. As the sustainable development of society, the strength and durability of the ordinary concrete are difficult to meet the requirement in some special fields as military project, underground waterproof engineering, and antiseismic structure. Steel fiber reinforced concrete (SFRC) is a kind of new multiphase composite material consisted of randomly distributed steel fibers, cement mortar, aggregate, interface, and pore. The steel fibers in SFRC can effectively prevent the formation and expansion of the microcracks and macrocracks in concrete and significantly enhance the tensile, flexural, shear, anticracking property, fatigue resistance as well as ductility after failure of concrete, compared with the ordinary concrete [1-4]. SFRC has been widely used in engineering constructions, such as road surface, airport runway, bridge deck pavement, floating dock, structural component, and so on.

Although the SFRC has superior physical and mechanical properties, the traditional mechanical crushing methods, such as vibration hammer, pickaxe, artillery, and other equipment, have certain limitations in the maintenance or demolition of SFRC buildings and structures. There are many disadvantages in quality, safety, and environmental protection such as large labor intensity, a lot of dust, and secondary damage to the original structure caused by a large number of vibrations. Different from the traditional mechanical methods, water jet is a new crushing method and has the advantages of high performance, no pollution, and 
selective crushing, which has the broad application prospects in the field of concrete crushing.

For the water jet breaking the ordinary concrete and rock materials, scholars have carried out some experimental explorations; for instance, Hood et al. [5] revealed the failure mechanism of rock impacted by water jet and proposed a model of predicting the broken depth. Momber and Kovacevic [6] studied the damage situation of concrete under different water jet velocity and impact time. Sitek et al. [7] analyzed the removal effect of concrete impacted by the pulsed water jet and continuous water jet. Sevda and Hood [8] studied the internal breaking ability of rock under pulsed water jet impact. Piush et al. [9] measured the depth, width, and volume of sandstone eroded by continuous water jet and pulsed water jet. Rupam et al. [10] studied the surface morphology of granite impacted by continuous water jet and pulsed water jet. These studies provide the theoretical basis for the further research studies concerning water jet impacting SFRC.

In recent years, scholars have conducted extensive research studies on the failure characteristics of SFRC and the ordinary concrete. For example, through the splitting experiment, Su et al. [11, 12] discovered that the ordinary concrete will form the smooth through fracture surfaces in the ordinary concrete with splitting failure, while SFRC only forms partial cracks generally, and the splitting performance is related to the volume fraction of steel fiber. Through the bending toughness experiment, Zhu et al. [13], Soulioti et al. [14], and Gao et al. [15] found that the ordinary concrete will enter the rapid destruction stage after cracking under bending load, while SFRC still has a certain bearing capacity after cracking, and the shape can maintain integrity in a period of time. Through the compressing experiment, Jiao et al. [16] and Xu et al. [17] found that SFRC and the ordinary concrete will present different final failure models under compression, the ordinary concrete shows columnar crushing, while SFRC shows shear failure. According to the above research studies, it can be found that the mechanical properties of SFRC are complex, and the fracture characteristics of SFRC subjected to the external loads are obviously different from the ordinary concrete. Therefore, it is necessary to carry out research studies on the mechanical properties of water jet impacting SFRC. Nevertheless, experimental means to explore the failure mechanism have some limitations; for instance, computed tomography (CT) technique cannot record accurately the dynamic fragmentation process. The high-speed camera is limited to the macroscopic and external perspectives, which cannot capture the internal and microscopic fragmentation state of concrete. Acoustic emission (AE) technology can only monitor the internal fracture signal of concrete, but there are still some problems such as noise, interference, difficult signal analysis, and so on.

Recently, the smoothed particle hydrodynamics (SPH) method has been successfully applied in numerical simulation to solve the problems of large deformation, high velocity, high strain rate, and high pressure caused by explosion, shock, and other loadings, and it provides an effective technical means for us to implement the in-depth studies. By establishing the numerical models based on the SPH method, Benz and Asphaug [18] and Rabczuk and Eibl [19] studied the fracture process of solids and fracture of concrete under explosive load, respectively. Liu et al. [20] built the numerical model of water jet impacting rock using the SPH method and studied the rock-breaking efficiency under different parameters. Pramanik and Deb [21] used the SPH method to study the rock-breaking mechanism under explosive load. Liu et al. [22] revealed the formation mechanism of concrete with the initial crack impacted by water jet by the SPH method. Zhang et al. [23] established the numerical model of projectiles impacting the concrete targets using the SPH method and studied the dynamic failure of concrete. Saba et al. [24] simulated the failure process of granite under blasting based on the SPH method and analyzed the failure characteristics and expansion of cracks. Above numerical simulation studies provide the technical reference for establishing the numerical model of water jet impacting SFRC.

Due to the good mechanical properties of SFRC, we must use ultra-high-pressure water jet (UHP-WJ) to break it. So, this paper attempts to establish numerical models of UHPWJ impacting SFRC based on the SPH method and records dynamic fracture process of SFRC and process of crack initiation and propagation. By damage characteristic analyses based on digital image processing technology, this paper also explores the breaking mechanism and damage evolution rule of SFRC under UHP-WJ impact. Results have the theoretical significance and practical value to improve the application level of UHP-WJ crushing SFRC technology and can help UHP-WJ to be better applied in maintenance and repair of SFRC structures.

\section{Numerical Model}

2.1. Geometrical Model. In this paper, effects of the entrainment and surface waveform separation of UHP-WJ on SFRC-breaking are not considered. Geometric model dimensions of UHP-WJ and concrete were $1.0 \mathrm{~mm} \times 100.0 \mathrm{~mm}$ and $100.0 \mathrm{~mm} \times 100.0 \mathrm{~mm}$, respectively. The initial velocity of the jet was $600.0 \mathrm{~m} / \mathrm{s}$, and the impact angle was $90^{\circ}$. Besides, this paper utilized ultra-fine copperplated steel fiber with the size of $0.22 \mathrm{~mm} \times 13.0 \mathrm{~mm}$. The steel fibers were randomly distributed in the concrete, as shown in Figure 1.

2.2. Constitutive Model of UHP-WJ. UHP-WJ adopted the NULL material model and was given the state equa shear destruction tion of GRUNEISEN as shown in the following equation:

$$
P=\frac{\rho_{0} C^{2} \mu\left[1+\left(1-\left(\gamma_{0} / 2\right)\right) \mu-(a / 2) \mu^{2}\right]}{\left[1-\left(S_{1}-1\right) \mu-S_{2}\left(\mu^{2} / \mu+1\right)-S_{3}\left(\mu^{3} /(\mu+1)^{2}\right)\right]^{2}}+\left(\gamma_{0}+a \mu\right) E .
$$

In the formula, $P$ is the pressure, $\rho_{0}$ is the initial density, $\mu$ is the viscosity coefficient, $E$ is the internal energy per unit volume, $C$ is the intercept of curve between shock wave 


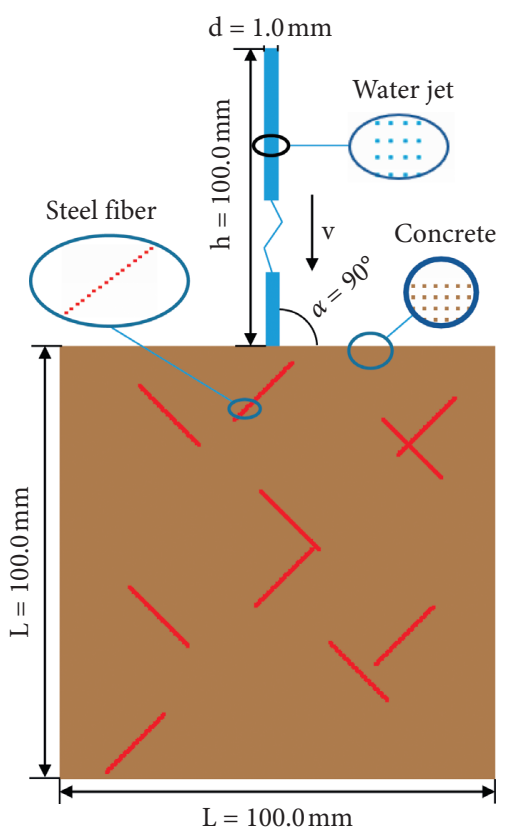

FIgUre 1: Geometric model of UHP-WJ impacting SFRC.

velocity and particle velocity $\left(v_{\mathrm{s}}-v_{\mathrm{p}}\right), S_{1}, S_{2}$, and $S_{3}$ are the slope of the $v_{\mathrm{s}}-v_{\mathrm{p}}$ curve, $\gamma_{0}$ is the Gruneisen constant, and $a$ is the correction coefficient of the relation between Gruneisen coefficient and volume. Constitutive model parameters of UHP-WJ are shown in Table 1.

\subsection{Constitutive Model and Failure Criterion of Concrete.} The constitutive model of Johnson-Holmquist concrete (JHC) was adopted for the concrete. The model comprehensively considers the effects of high hydrostatic pressure, high strain rate, and damage, which can reflect the nonlinear deformation of concrete under hydraulic impact [25]. The strength was described by the normalized equivalent stress as shown in the following equation:

$$
\sigma^{*}=\left[A(1-D)+B P^{* N}\right]\left[1-C \ln \varepsilon^{*}\right] .
$$

In Equation (2), $\sigma *=\sigma / f_{\mathcal{c}}$, where $\sigma * \leq S_{\max }, \sigma *$ is the normalized equivalent stress, $S_{\max }$ is the maximum normalized equivalent stress, $\sigma$ is the actual yield strength, and $f_{c}$ is the quasi-static uniaxial compressive strength; $P^{*}=P / f_{\mathrm{c}}$, where $P *$ is the normalized equivalent hydrostatic pressure and $P$ is the hydrostatic pressure; $\varepsilon *=\varepsilon / \varepsilon_{0}$, where $\varepsilon *$ is the normalized strain rate, $\varepsilon$ is the actual strain rate, and $\varepsilon_{0}$ is the reference strain rate with the value of $1.0 \mathrm{~s}^{-1} ; A$ is the characterized cohesive strength parameter; $B$ is the characterized pressure hardening coefficient; $C$ is the strain rate effect coefficient; $N$ is the characteristic pressure hardening index; and $D$ is the damage variable.

Generally, the failure type of brittle materials impacted by UHP-WJ is tensile or shear destruction. In order to study the crack formation and propagation mechanism of concrete under hydraulic impact, the dynamic failure criterion in Equation (3) was used to determine the failure behavior of concrete:
TABLE 1: Conductive parameters for UHP-WJ.

\begin{tabular}{lccccccc}
\hline$\rho_{0}\left(\mathrm{~g} \bullet \mathrm{cm}^{-3}\right)$ & $C\left(\mathrm{~m} \bullet \mathrm{s}^{-1}\right)$ & $S_{1}$ & $S_{2}$ & $S_{3}$ & $a$ & $\gamma_{0}$ & $E$ \\
\hline 1.00 & 1480 & 2.56 & -1.986 & 0.2286 & 1.397 & 0.49 & 0 \\
\hline
\end{tabular}

$$
\sigma_{1} \geq[\sigma] \text { or } \tau_{\max } \geq[\tau] .
$$

In the formula, $\sigma_{1}$ is the maximum principal stress, $[\sigma]$ is the dynamic tensile strength of concrete, $\tau_{\max }$ is the maximum shear stress, and $[\tau]$ is the dynamic shear strength of concrete.

Due to the effect of strain rate on concrete under dynamic loading, the strength of concrete increases with the increase in strain rate before the strength of concrete reaches an extreme value [26]. And the dynamic tensile strength or dynamic shear strength is approximately certain multiple of the quasi-static tensile strength or quasi-static shear strength. In view of this, according to the general rule between the dynamic strength and the quasi-static strength of concrete, the numerical simulations of UHP-WJ crushing concrete with different mechanical parameters and a large number of experiments were conducted. The mechanical properties of concrete under hydraulic impact were obtained by comparing the numerical simulations with the experimental failure modes, as shown in Table 2.

2.4. Constitutive Model of Steel Fiber. The model of Mat_Plastic_Kinematic (MAT_003) has the strain rate effect and can be used for isotropic and kinematic hardening. The material model has been widely applied to simulate the steel fiber material, and the constitutive equation is expressed as follows:

$$
\sigma_{y}=\left[1+(\varepsilon / c)^{(1 / p)}\right]\left(\sigma_{0}+\beta E_{p} \varepsilon_{\mathrm{eff}}^{p}\right) .
$$

In Equation (4), $\sigma_{\mathrm{y}}$ is the stress corresponding to $\varepsilon_{\text {eff }}^{p}$ strain rate, $\sigma_{0}$ is the initial yield stress, $\dot{\varepsilon}$ is the strain rate, and $C$ and $P$ are the strain rate parameters. When $C$ and $P$ are set to 0 , it is independent of the rate. $\varepsilon_{\text {eff }}^{p}$ is the effective plastic strain. $E_{\mathrm{p}}$ is the plastic hardening modulus. And when $E_{\mathrm{P}}$ is 0 , the material is considered as elastic material. $\beta$ is the hardening parameter between 0 and 1 , which can represent motion hardening, isotropic hardening, or a combination of motion hardening and isotropic hardening. Steel fibers in concrete were simulated utilizing the constitutive model of MAT_003, and its parameters are shown in Table 3. E is Young's modulus, and PR is Poisson's ratio.

\section{Results and Discussion}

3.1. Crater Formation. At the initial stage of hydraulic impact, there was a certain distance between the steel fiber and solid-liquid contact area, so the solid-liquid contact area was the weak effect zone of steel fiber, and the SFRC had small failure. Under the impact of UHP-WJ, the failure of SFRC symmetrically developed and finally a bowl-shaped crater was generated, as demonstrated in Figure 2(a). It can be found that the failure features of SFRC in the initial stage of hydraulic impact were basically consistent with those of 
TABLE 2: Conductive parameters for the concrete.

\begin{tabular}{lcccccccc}
\hline$\rho_{0} /\left(\mathrm{g} \bullet \mathrm{cm}^{-3}\right)$ & $f_{c}(\mathrm{MPa})$ & $A$ & $B$ & $C$ & $N$ & $S_{\max }$ & $\sigma(\mathrm{MPa})$ & $\tau(\mathrm{MPa})$ \\
\hline 2.10 & 40 & 0.79 & 1.60 & 0.007 & 0.61 & 7 & 15.1 & 68.1 \\
\hline
\end{tabular}

TABLe 3: Material parameters for steel fiber.

\begin{tabular}{lcccccc}
\hline$\rho_{0}\left(\mathrm{~g} \cdot \mathrm{cm}^{-3}\right)$ & $E(\mathrm{GPa})$ & $P R$ & $\sigma_{0}(\mathrm{GPa})$ & $C\left(\mathrm{~ms}^{-1}\right)$ & $P$ & $E_{\mathrm{p}}(\mathrm{GPa})$ \\
\hline 7.8 & 200 & 0.3 & 0.5 & 40.4 & 5 & 3.09 \\
\hline
\end{tabular}

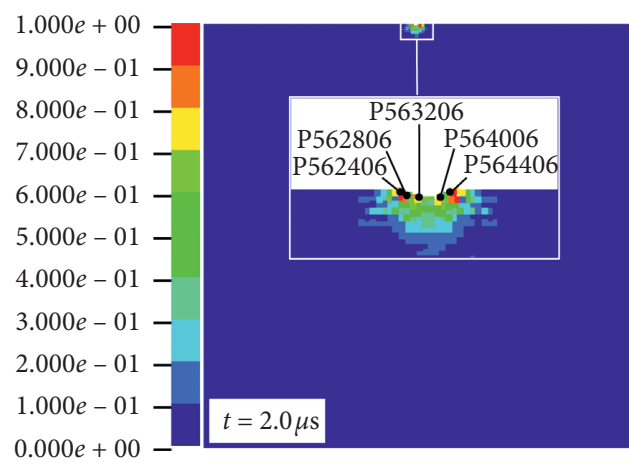

(a)

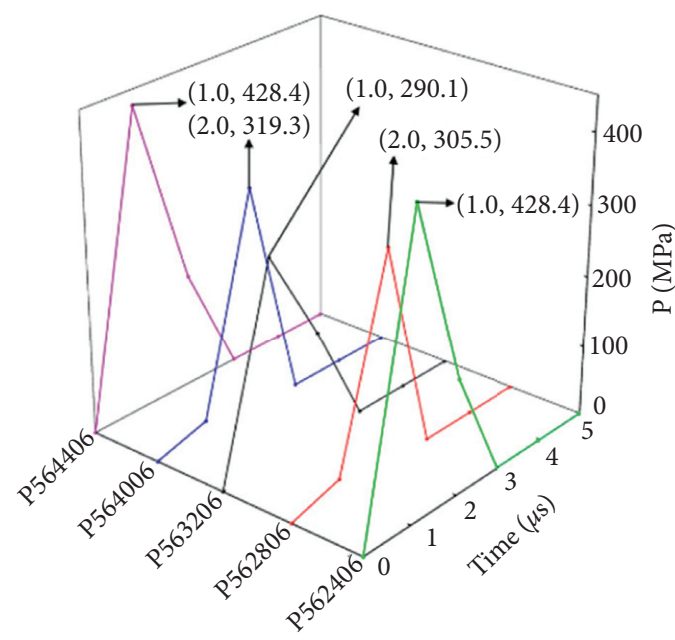

(b)

FIgURE 2: Crater formation of SFRC. (a) Appearance of crater. (b) Pressure curves of typical particles in solid-liquid contact area.

the ordinary concrete. At the moment of contact between the UHP-WJ and SFRC, the sudden drop of the UHP-WJ velocity induced the strong water hammer effect, causing the sharp increase in particle pressure in the solid-liquid contact area. As shown in Figure 2(b), the particle pressure reached a higher level in a short period of time, but the pressure decreased rapidly due to the straight front of UHP-WJ and the short duration of the water hammer effect $[27,28]$.

In the process of UHP-WJ impacting SFRC, when the stress of concrete particle exceeds its strength, the particle is failed and the concrete is broken. To reveal the formation mechanism of crater, this paper extracted the stresses of five typical particles in solid-liquid contact area and obtained the stress curves of these particles as displayed in Figure 3. The maximum compressive stress and the maximum shear stress of particle P562406 were 514.4 MPa and 80.2 MPa, respectively, at $t=1 \mu \mathrm{s}$, which correspondingly exceeded the compressive strength and shear strength. Similarly, the maximum compressive stresses and the maximum shear stresses of the four particles all exceeded the strength that the particles can bear. Therefore, it can be recognized that the particles in the liquid-solid contact area are mainly destroyed by the combined action of compressive stress and shear stress, and the SFRC takes place failure. The failure of
SFRC gradually develops along the direction of UHP-WJ impact and finally a bowl-shaped crater is produced.

\subsection{Damage Development of Concrete in the Effect Area of Steel Fiber}

3.2.1. Stage I: Formation of Crack along the Steel Fiber. Although the duration of water hammer effect was short and the pressure at the liquid-solid contact area was quickly reduced to the more stable Bernoulli stagnation pressure, the stagnation pressure was still at a high level and was transmitted to the interior of SFRC in the form of stress waves. Under the actions of the stress waves, the crater of SFRC developed downwards, and concrete on the upper end of steel fiber was broken firstly. Due to the remarkable inhomogeneity of the contact area between steel fiber and concrete, when the stress waves propagated to the contact surface between steel fiber and concrete, the obvious stress concentration was produced in the contact surface, causing the formation of a microcrack along the steel fiber. With the expansion of microcrack, a macrocrack along the steel fiber was generated, as shown in Figure 4. 


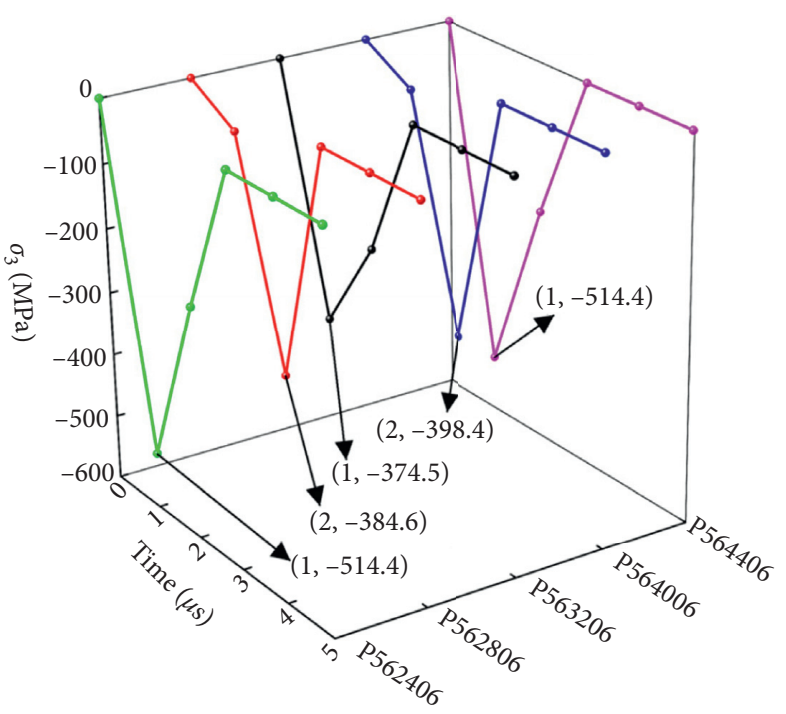

(a)

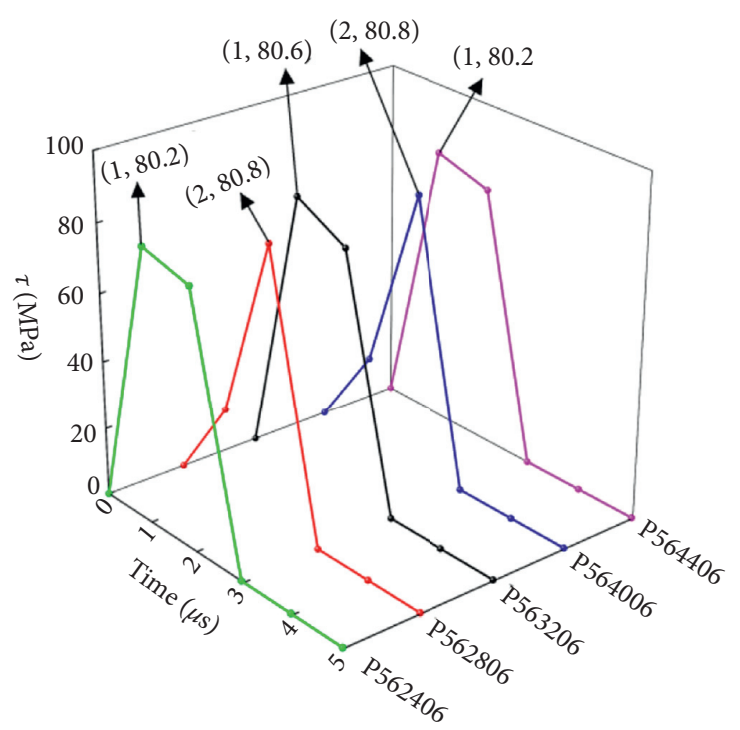

(b)

Figure 3: Stress curves of typical particles in the solid-liquid contact area: (a) compressive stress; (b) shear stress.

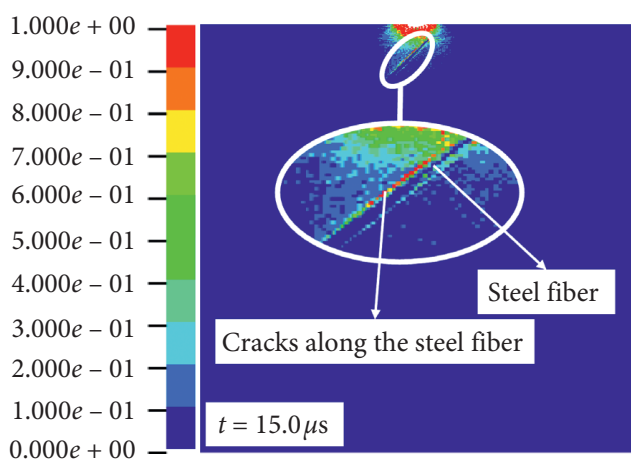

FIgURE 4: Crack appearance along the steel fiber.

3.2.2. Stage II: Obstruction Effect of Steel Fiber. After the formation of macrocrack along the steel fiber, the damage area on the upper of the steel fiber continued to develop with the further impact of UHP-WJ. Compared with the ordinary concrete, the steel fiber in SFRC had the strong toughness and can absorb certain energy carried by UHP-WJ, which hindered the evolution of damage and caused the difference of damage degree on the upper and lower sides of the steel fiber. Thus, the steel fiber had the certain obstruction effect to the development of concrete damage, as presented in Figure 5.

3.2.3. Stage III: Fusion of Broken Bodies on the Upper and Lower Sides of Steel Fiber. The damage developments on the upper and the lower sides of the steel fiber had certain differences under the obstruction effect of steel fiber, but with the sustained impact of UHP-WJ, the steel fiber located in the strong-radiation area of stress waves transferred from fluid-solid contact center first took place fracture and then the stress waves can quickly propagate to the lower side of

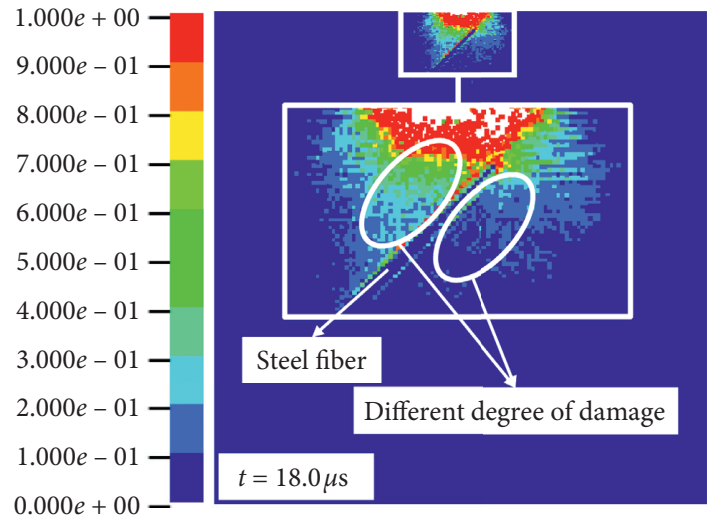

Figure 5: Obstruction effect of steel fiber.

steel fiber. Under the action of stress waves, the damage areas of concrete on the upper and lower sides of steel fiber constantly expanded and finally the broken bodies on the upper and lower sides of steel fiber fused into a complete crater, as demonstrated in Figure 6.

Results can help to predict the crack expansion state and evolution process of SFRC impacted by UHP-WJ, speculate the damage state in the near region of SFRC, and evaluate the whole fragmentation degree of SFRC, and it provides the theoretical significance for improving the application level of UHP-WJ crushing SFRC technology and shifting the emergency demolition ability of SFRC buildings and structures after disaster.

3.3. Experimental Verification. To verify the reliability of the UHP-WJ impacting SFRC numerical simulation, the hydraulic impact experiment of SFRC was carried out by the cantilever cutting machine of JJ-I42*1313 manufactured by 


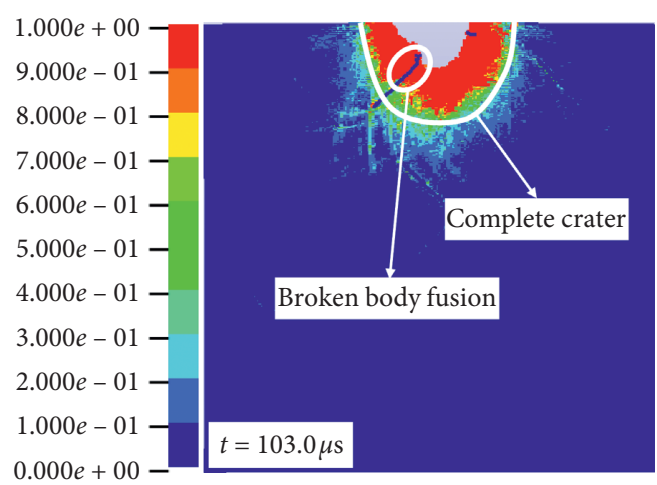

FIGURE 6: Fusion of broken bodies on the upper and lower sides of steel fiber.

Shanghai Jinjian water jet equipment manufacturing company. And the CT scanning device was utilized to detect the internal destruction. The experimental devices and working procedure are presented in Figure 7. By comparatively analyzing the numerical simulation and experimental results in Figure 8(a), it can be found that there was the obvious bowl-shaped crater on the surface of SFRC in the numerical simulation, whereas in the impact experiment of UHP-WJ, the SFRC took place the cracking and the splitting of free block in the near region of erosion hole, forming an initial and annular crack. And the annular crack had the irregular shape due to the initial defects of materials and uneven impact of UHP-WJ. In numerical simulation and experiment, there was no macroscopic and interlaced crack, which reflects the consistent characteristic.

In addition, the numerical simulation and experimental results of UHP-WJ impacting the ordinary concrete are analyzed as a comparison for SFRC. As shown in Figure 8(b), the breaking effect, shape of crater, and expansion pattern of crack in experiment are basically consistent with those in numerical simulation. Compared with the ordinary concrete, the failure of SFRC subjected to UHP-WJ impact is limited to the finite range with lower dimension of crater, and it is difficult to produce the macroscopic cracks.

According to abovementioned analysis, although there are certain differences between the experiment and the numerical simulation results, the basically similar failure features can verify the correctness of numerical simulation of UHP-WJ impacting SFRC.

3.4. Quantification and Comparison of Damage. On the basis of digital image processing technology, the damage images of SFRC and the ordinary concrete were segmented at the pixel level to divide the damage into 10 grades. Then, the color gamut images corresponding to each damage grade were extracted, as displayed in Table 4. To quantitatively analyze the failure of SFRC and the ordinary concrete, the comprehensive damage factor was defined as follows:

$$
X=\frac{0.1 S_{2}+0.2 S_{3}+0.3 S_{4}+0.4 S_{5}+0.5 S_{6}+0.6 S_{7}+0.7 S_{8}+0.8 S_{9}+0.9 S_{10}}{S} .
$$

In the equation, $S$ is the total area of concrete section, and the parameters from $S_{1}$ to $S_{10}$ are the areas in the region of the damage grades from I to $\mathrm{X}$. The damage of concrete is small when the damage grade is I, so the damage is ignored.

To quantitatively study the damage distribution of SFRC and the ordinary concrete under UHP-WJ impact, the damage images of SFRC and the ordinary concrete were divided into five parts along the axial and radial directions of the impact center. Then, the comprehensive damage factors in each part were calculated, as shown in Figures 9 and 10. According to the calculated values, the comprehensive damage factor was divided into different grades by marking different colors.

By the comparative analyses of comprehensive damage factors of SFRC and the ordinary concrete, in the axial direction, the comprehensive damage factors of SFRC in regions (1)-I, (1)-II, and (1)-III were 0.3749, 0.0334, and $3.56 \times 10^{-5}$, respectively, which were smaller than those in the corresponding regions of the ordinary concrete. In the axial direction, the comprehensive damage factors of SFRC were smaller than those of the ordinary concrete. Therefore, it can be concluded that the fragmentation degrees of UHPWJ impacting SFRC in the axial and radial directions are lower than those of concrete.
Besides, the average comprehensive damage factors of SFRC and the ordinary concrete in the axial and radial directions were plotted to study the variation rule of damage from the impact center to the surroundings. By the analysis along axial direction in Figure 11, it can be found that from the area I to area II, the attenuation rate of comprehensive damage factor for SFRC reached to $93.8 \%$, which was higher than that of the ordinary concrete $(81.6 \%)$. From region II to region III, the attenuation rate of comprehensive damage factor for SFRC was $100 \%$, and the ordinary concrete had the attenuation rate of $96.8 \%$ approaching to the complete attenuation. Further, by the analysis along radial direction in Figure 12, from the area (1) to the L-area (2), the average attenuation rate of comprehensive damage factor for SFRC was $69.5 \%$, which was higher than that of the ordinary concrete $(57.9 \%)$. From the area (1) to the R-area (2), the attenuation rate of comprehensive damage factor for SFRC was close to that of the ordinary concrete. From the L-area (2) to the L-area (3), the average attenuation rate of the comprehensive damage factor for SFRC was almost the same as that of the ordinary concrete. Nevertheless, from the $\mathrm{R}$-area (2) to the R-area (3), the attenuation rate of comprehensive damage factor for SFRC was $97.0 \%$, which was much higher than that of the ordinary concrete (65.4\%). So, 


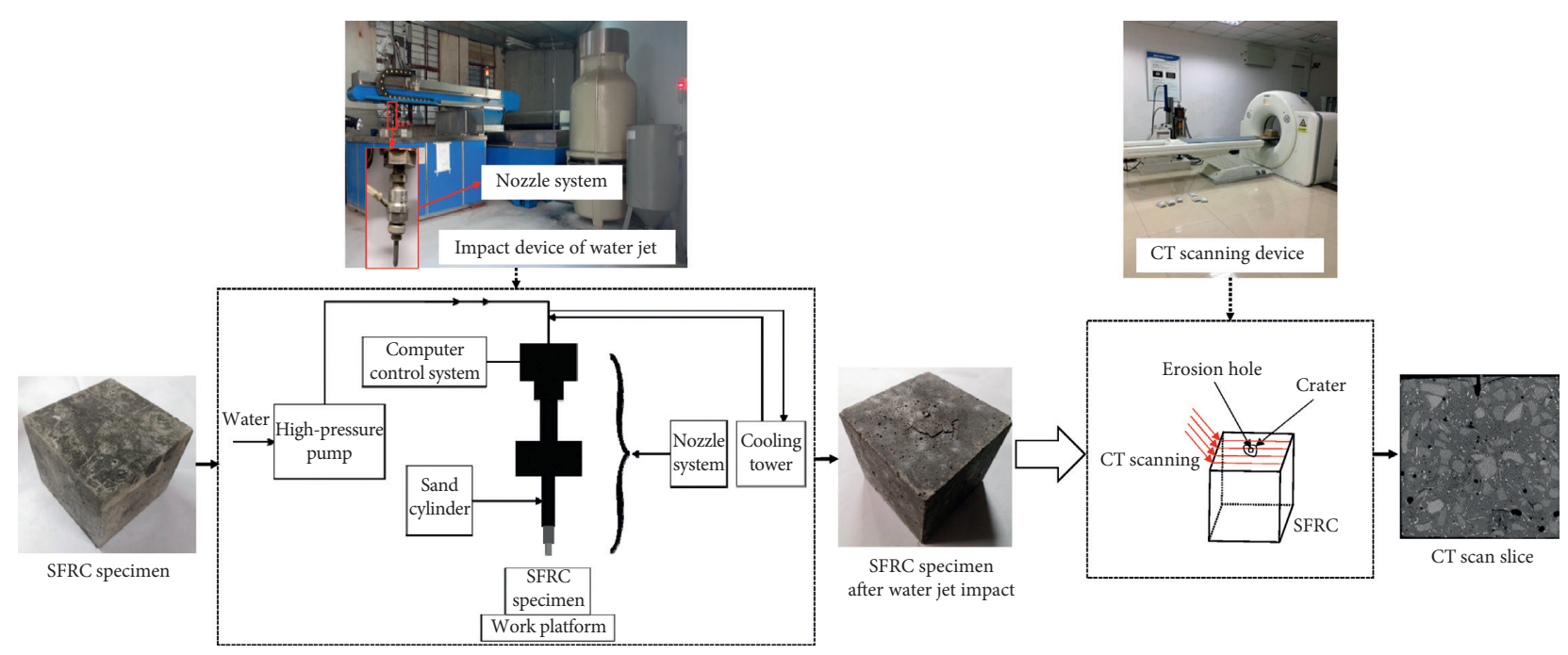

Figure 7: Experimental equipment and procedure.

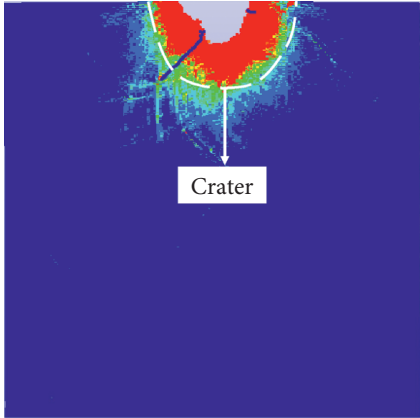

Numerical simulation result

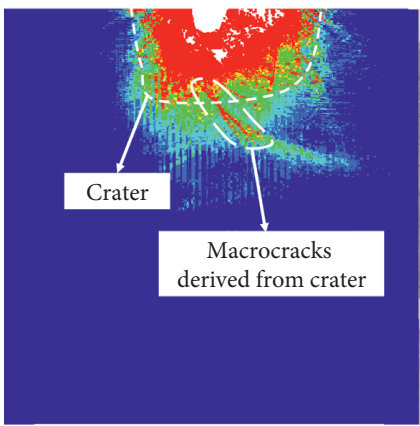

Numerical simulation result

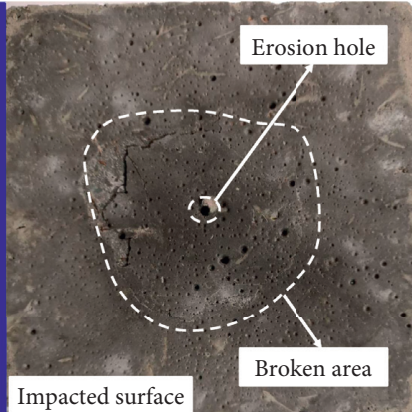

Experimental result of water jet impact

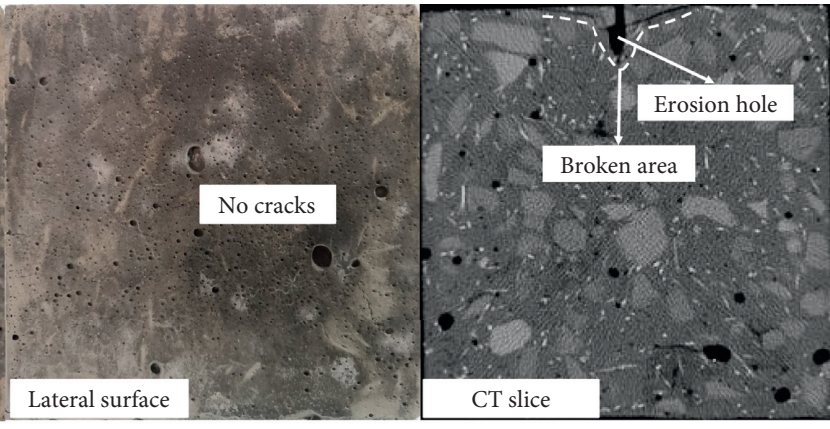

(a)

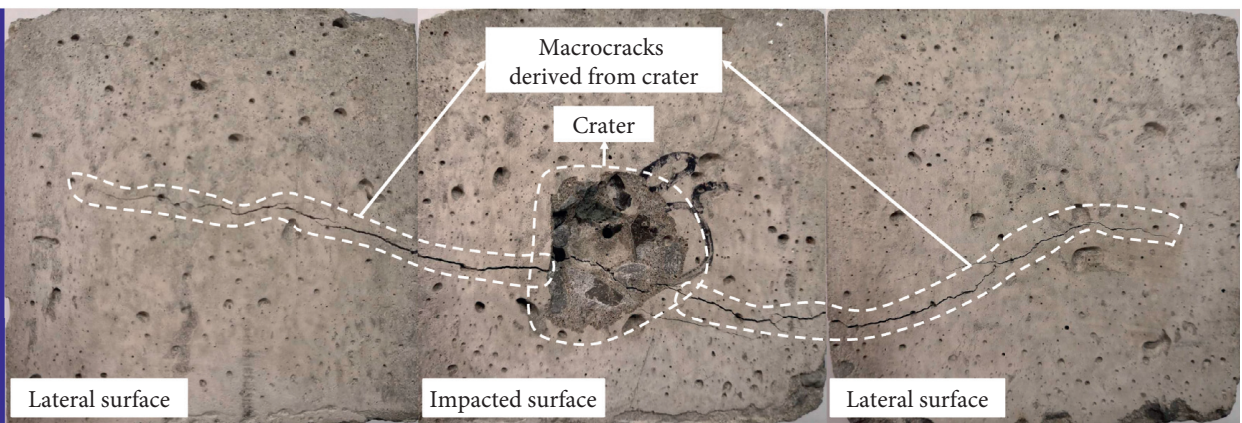

Experimental result of water jet impact
CT scanning result

(b)

FIGURE 8: Comparison of results in numerical simulation and experiment: (a) SFRC and (b) ordinary concrete.

the damage degrees of SFRC along the axial and radial directions are lower than those of the ordinary concrete, but the damage attenuation rates of SFRC along the axial and radial direction are higher than those of the ordinary concrete.

Different from the concrete material, the steel fiber has the intense toughness and can absorb the partial energy carried by UHP-WJ, hindering the propagations of stress waves in the interior of SFRC, so the damage development in the surroundings of steel fiber is obstructed. Moreover, because of the obstruction of steel fiber to the cracking of concrete, the anticracking property, fatigue resistance, and ductility after failure of concrete are significantly improved, compared with the ordinary concrete. 


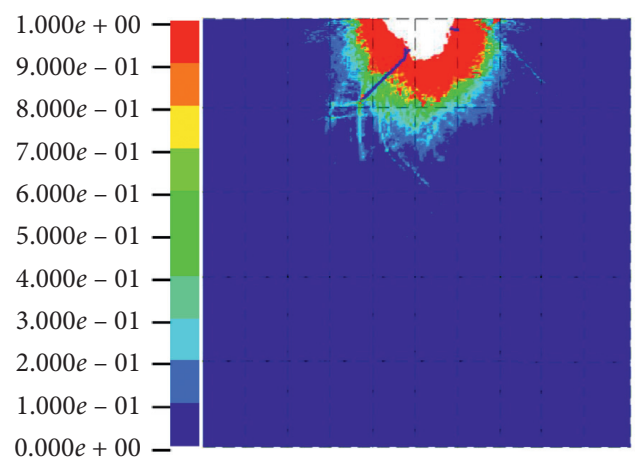

(a)

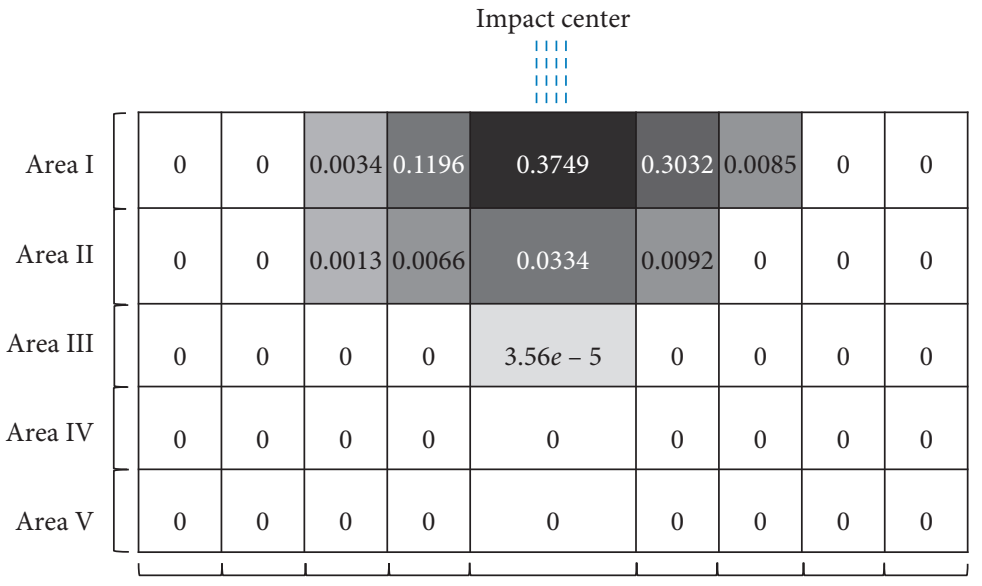

(5) (4) (3) (2)
(1)

(2)

(3)

(4)

(b)

FIgURE 9: Distributions of comprehensive damage factors in each part of SFRC.

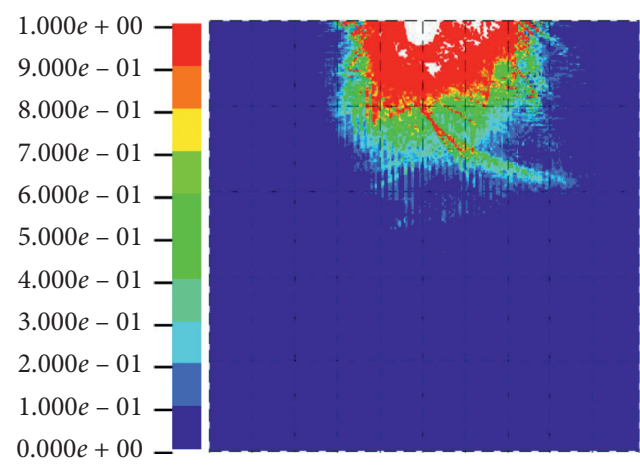

(a)

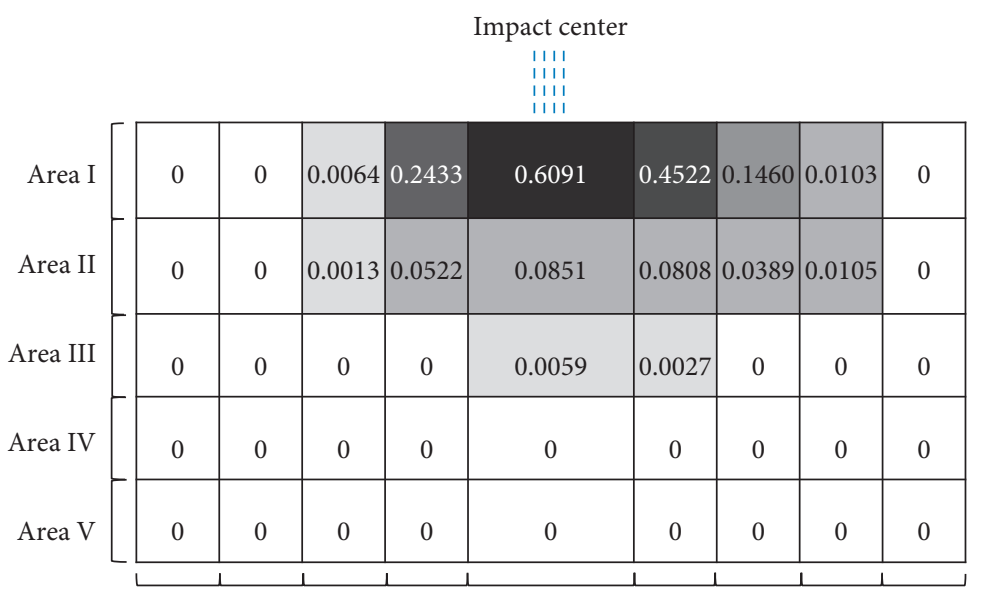

(5) (4) (3) (2)
(1)

(2)

(3)

(4)

(b)

FIGURE 10: Distributions of comprehensive damage factors in each part of the ordinary concrete.

TABLE 4: Color gamut comparison of SFRC and the ordinary concrete with different damage grades.

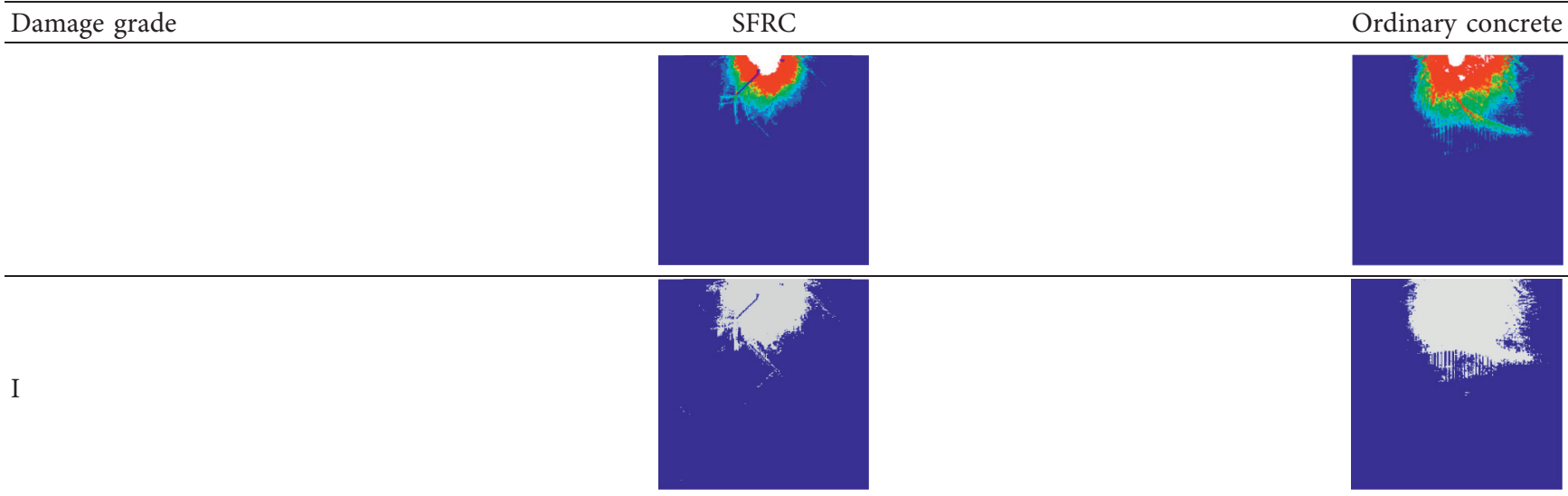


TABle 4: Continued.

\begin{tabular}{|c|c|c|}
\hline Damage grade & SFRC & Ordinary concrete \\
\hline II & & \\
\hline \multicolumn{3}{|l|}{ III } \\
\hline \multicolumn{3}{|l|}{ IV } \\
\hline \multicolumn{3}{|l|}{ V } \\
\hline \multicolumn{3}{|l|}{ VI } \\
\hline \multicolumn{3}{|l|}{ VII } \\
\hline \multicolumn{3}{|l|}{ VIII } \\
\hline \multicolumn{3}{|l|}{ IX } \\
\hline $\mathrm{x}$ & & \\
\hline
\end{tabular}




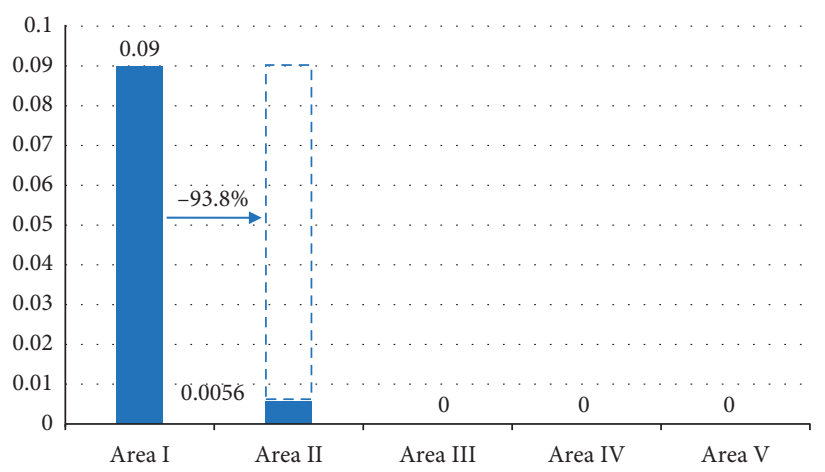

- Comprehensive damage factor

(a)

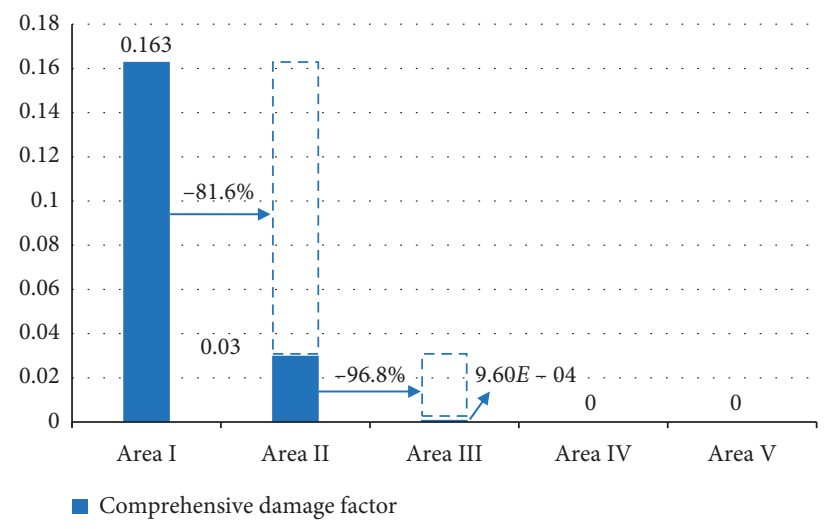

(b)

FIGURE 11: Comparison of average comprehensive damage factors in the axial direction: (a) SFRC and (b) ordinary concrete.

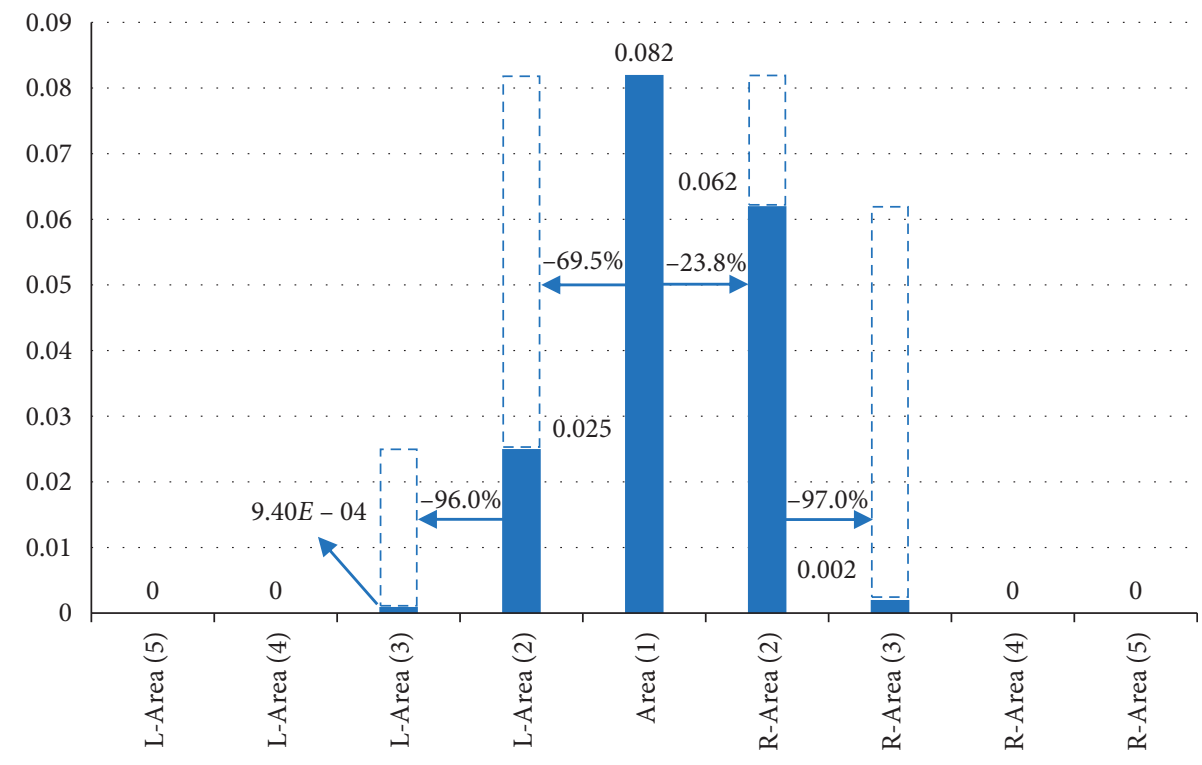

- Comprehensive damage factor

(a)

Figure 12: Continued. 


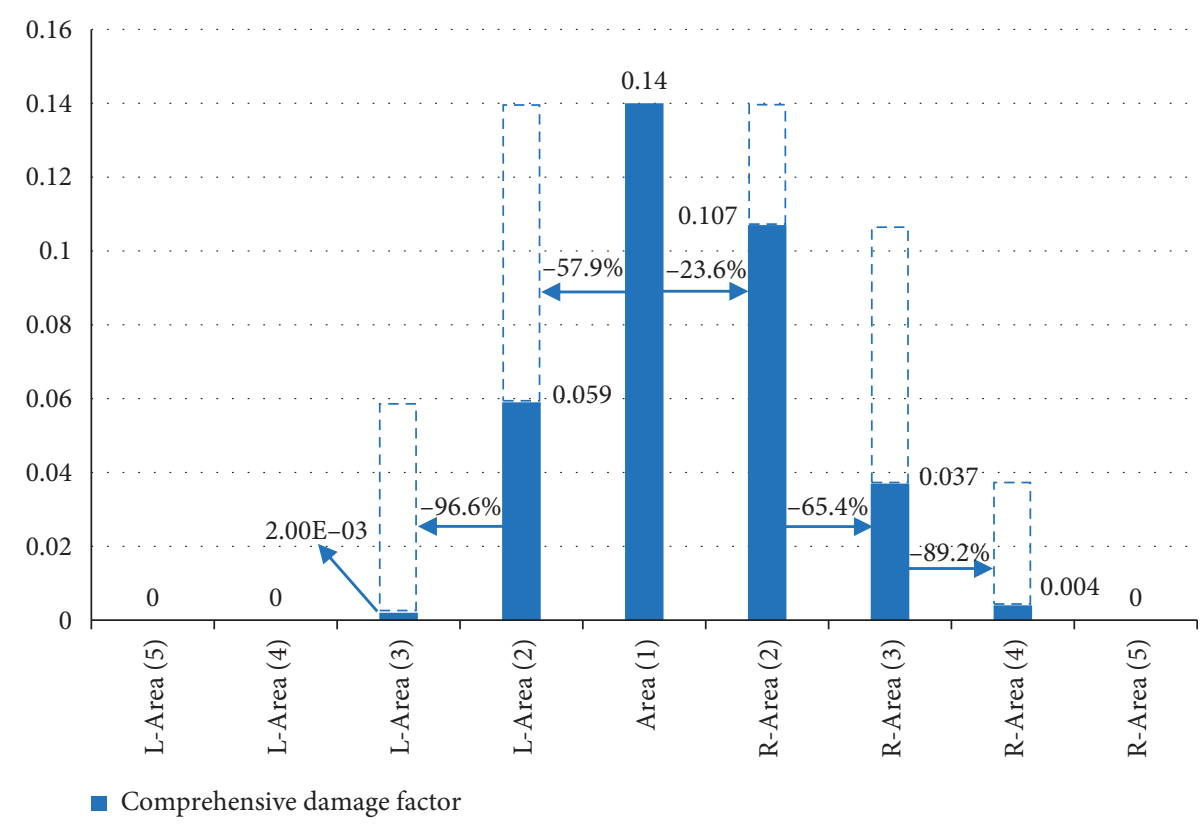

(b)

FIGURE 12: Comparison of average comprehensive damage factors in the radial direction: (a) SFRC and (b) ordinary concrete.

\section{Conclusion}

Base on the SPH method, this paper established the numerical model of UHP-WJ impacting SFRC, verified the established numerical model by UHP-WJ impacting SFRC and computed tomography (CT) scanning experiments, and revealed the breaking mechanism and damage evolution rule of UHP-WJ impacting SFRC.

(1) In the initial stage of UHP-WJ impact, the combining action of compressive stress and shear stress induces concrete failure in the weak effect zone of steel fiber. With the development of the failure along the axial direction of UHP-WJ, the crater is produced.

(2) In the affected area of steel fiber, due to the stress concentration in the inhomogeneous contact area of the steel fiber and concrete, microcracks along the steel fiber are formed and evolved into the propagated crack along the steel fiber. And the steel fiber obstructs the development of broken bodies on the upper and lower sides of steel fiber. With the sustained impact of UHP-WJ, the steel fiber in the strong-radiation region of stress wave transferred from fluid-solid contact center takes place fracture, so the obstruction phenomenon disappears and the fusion of broken bodies on the upper and lower sides of steel fiber occurs.

(3) Based on CT scans and digital image processing technology, this paper also comparatively analyzed the internal failure features of SFRC and the ordinary concrete subjected to UHP-WJ impact. Results show that compared with the ordinary concrete, the dimension of crater of SFRC is smaller, and it is difficult for SFRC to engender macroscopic crack. Besides, the SFRC has the smaller damage and higher damage attenuation in axial and radial directions.

\section{Data Availability}

The data used to support the findings of this study are included within the article.

\section{Conflicts of Interest}

The authors declare that they have no conflicts of interest.

\section{Acknowledgments}

This work was supported by the China Postdoctoral Science Foundation (grant no. 2020M683257), the General Fund of Chongqing Natural Science Foundation (grant no. cstc2020jcyj-msxm3094), and the National Natural Science Foundation of China (grant no. 51608082).

\section{References}

[1] M. C. Nataraja, N. Dhang, and A. P. Gupta, "Stress-strain curves for steel-fiber reinforced concrete under compression," Cement and Concrete Composites, vol. 21, no. 5-6, pp. 383-390, 1999.

[2] C. Frazão, A. Camões, J. Barros, and D. Gonçalves, "Durability of steel fiber reinforced self-compacting concrete," Construction and Building Materials, vol. 80, pp. 155-166, 2015.

[3] S. G. Nehme, R. László, and A. E. Mir, "Mechanical performance of steel fiber reinforced self-compacting concrete in panels," Procedia Engineering, vol. 196, pp. 90-96, 2017.

[4] C. Li, H. Geng, C. Deng, B. Li, and S. Zhao, "Experimental investigation on columns of steel fiber reinforced concrete 
with recycled aggregates under large eccentric compression load," Materials, vol. 12, no. 3, p. 445, 2019.

[5] M. Hood, R. Nordlund, and E. Thimons, "A study of rock erosion using high-pressure water jets," International Journal of Rock Mechanics and Mining Sciences \& Geomechanics Abstracts, vol. 27, no. 2, pp. 77-86, 1990.

[6] A. Momber and R. Kovacevic, "Fundamental investigations on concrete wear by high velocity water flow," Wear, vol. 177, no. 1, pp. 55-62, 1994.

[7] L. Sitek, J. Foldyna, P. Martinec, J. Ščučka, L. Bodnárová, and R. Hela, "Use of pulsating water jet technology for removal of concrete in repair of concrete structures," The Baltic Journal of Road and Bridge Engineering, vol. 6, no. 4, pp. 235-242, 2011.

[8] S. Dehkhoda and M. Hood, "The internal failure of rock samples subjected to pulsed water jet impacts," International Journal of Rock Mechanics and Mining Sciences, vol. 66, pp. 91-96, 2014.

[9] P. Raj, S. Hloch, R. Tripathi et al., "Investigation of sandstone erosion by continuous and pulsed water jets," Journal of Manufacturing Processes, vol. 42, pp. 121-130, 2019.

[10] R. Tripathi, S. Hloch, S. Chattopadhyaya, D. Klichová, J. Ščččka, and A. K. Das, "Application of the pulsating and continous water jet for granite erosion," International Journal of Rock Mechanics and Mining Sciences, vol. 126, Article ID 104209, 2020.

[11] C. Su, Y. Li, and Z. Xiong, "Strength and deformation properties of steel fiber reinforced high performance concrete under splitting process," Journal of Building Materials, vol. 17, no. 4, pp. 586-591, 2014.

[12] C. Su and H. Lin, "Mechanical performances of steel fiber reinforced high strength concrete disc under cyclic loading," Construction and Building Materials, vol. 146, pp. 276-282, 2017.

[13] H. Zhu, D. Gao, L. Xie, and Q. Zhang, "Research on flexural toughness of steel fiber reinforced high-strength concrete," Journal of the Chinese Ceramic Society, vol. 32, no. 5, pp. 656-660, 2004.

[14] D. V. Soulioti, N. M. Barkoula, A. Paipetis, and T. E. Matikas, "Effects of fibre geometry and volume fraction on the flexural behaviour of steel-fibre reinforced concrete," Strain, vol. 47, pp. 535-541, 2011.

[15] D. Gao, L. Zhao, F. Hu, and S. Zhao, "Flexural toughness and it's evaluation method of steel fiber reinforced concrete," Journal of Building Materials, vol. 17, no. 5, pp. 783-789, 2014.

[16] C. Jiao, J. Zhang, and W. Sun, "Experimental study on uniaxial compression of SFRC," Building Science, vol. 21, no. 5, pp. 1-5, 2005.

[17] W. Xu, Z. Liu, Y. Zhao, and S. Xu, "Experimental research on the uniaxial compression of steel fiber reinforced ultra-high performance concrete," Industrial Construction, vol. 46, no. 12, pp. 104-109, 2016.

[18] W. Benz and E. Asphaug, "Simulations of brittle solids using smooth particle hydrodynamics," Computer Physics Communications, vol. 87, no. 1-2, pp. 253-265, 1995.

[19] T. Rabczuk and J. Eibl, "Simulation of high velocity concrete fragmentation using SPH/MLSPH," International Journal for Numerical Methods in Engineering, vol. 56, no. 10, pp. 14211444, 2010.

[20] X. Liu, S. Liu, and H. Ji, "Numerical research on rock breaking performance of water jet based on SPH," Powder Technology, vol. 286, pp. 181-192, 2015.

[21] R. Pramanik and D. Deb, "Implementation of smoothed particle hydrodynamics for detonation of explosive with application to rock fragmentation," Rock Mechanics and Rock Engineering, vol. 48, no. 4, pp. 1683-1698, 2015.

[22] J. Liu, D. Zhang, S. Du, and H. Wang, "Crack formation mechanism of concrete with an initial crack under hydraulic impacting," Journal of Vibration and Shock, vol. 39, no. 14, pp. 130-135, 2020.

[23] S. Zhang, X. Kong, Q. Fang, L. Chen, and Y. Wang, "Numerical prediction of dynamic failure in concrete targets subjected to projectile impact by a modified Kong-Fang material model," International Journal of Impact Engineering, vol. 144, Article ID 103633, 2020.

[24] S. Gharehdash, M. Barzegar, I. B. Palymskiy, and P. A. Fomin, "Blast induced fracture modelling using smoothed particle hydrodynamics," International Journal of Impact Engineering, vol. 135, Article ID 103235, 2020.

[25] T. J. Holmquist, G. R. Johnson, and W. H. Cook, “A Computational constitutive model for concrete subjective to large strain, high strain rates, and high pressure," in Proceedings of the 1th International Symposium on Ballistic, pp. 591-600, Quebec City, Canada, November 1993.

[26] L. Javier Malvar, J. E. Crawford, J. W. Wesevich, and D. Simons, "A plasticity concrete material model for DYNA3D," International Journal of Impact Engineering, vol. 19, no. 9-10, pp. 847-873, 1997.

[27] F. J. Heymann, "High-speed impact between a liquid drop and a solid surface," International Journal of Applied Physics, vol. 40, no. 13, pp. 5112-5122, 1969.

[28] J. E. Field and M. B. Lesser, “, J. P. Dear. Studies of twodimensional liquid-wedge impact and their relevance to liquid-drop impact problems," Proceedings of the Royal Society of London Series A, Mathematical and Physical Sciences, vol. 401, no. 1821, pp. 225-249, 1985. 